\title{
Disseminated necrotizing leukoencephalopathy
}

\section{Leucoencefalopatia necrotizante disseminada}

Matthew R. McCann', Ana C. Albujaำ, Mauricio F. Villamar', Douglas E. Lukins²

An 11-year-old boy had a relapse of acute lymphoblastic leukemia involving the CNS. He was treated with whole brain radiotherapy and intrathecal methotrexate. One week after the whole brain radiotherapy, he developed personality changes and right facial weakness. Brain MRI was obtained (Figure 1).

Disseminated necrotizing leukoencephalopathy is an uncommon neurotoxicity syndrome associated with whole brain radiotherapy and methotrexate. Personality change is commonly reported ${ }^{1}$. Disseminated necrotizing leukoencephalopathy is characterized by subcortical T2-hyperintensities with low-signal foci and corresponding contrast-enhancing areas $^{1,2}$. Early cessation of inciting therapies may prevent progression (Figure 2). Our patient returned to his neurologic baseline and at 14-month follow-up remained without further deterioration.
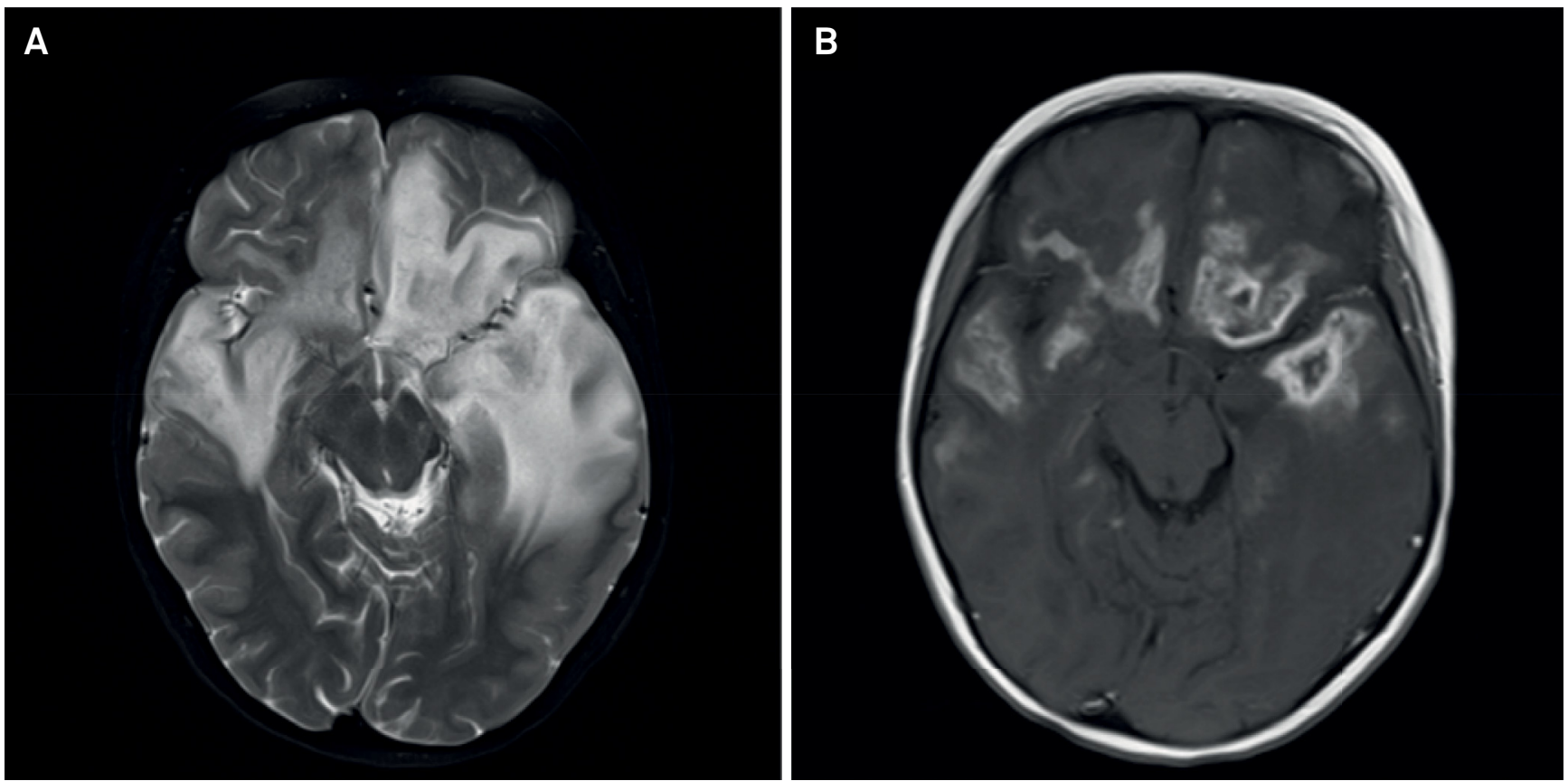

Figure 1. Initial brain MRI. Axial T2-weighted brain MRI shows extensive regions of subcortical hyperintensity with small internal foci of low signal (A). Post-contrast T1-weighted axial MRI shows a necrotic-appearing subcortical enhancement pattern within the anterior temporal and inferior frontal lobes bilaterally (B).

${ }^{1}$ University of Kentucky, Department of Neurology, Lexington, KY, USA; ${ }^{2}$ University of Kentucky, Department of Radiology, Lexington, KY, USA.

Correspondence: Matthew R. McCann; Department of Neurology, University of Kentucky; 740 South Limestone St, Kentucky Clinic - J464, Lexington, KY 40536-0284; E-mail: mattmccann80@gmail.com

Conflict of interest: There is no conflict of interest to declare.

Received 27 June 2018; Received in final form 02 August 2018; Accepted 08 August 2018. 


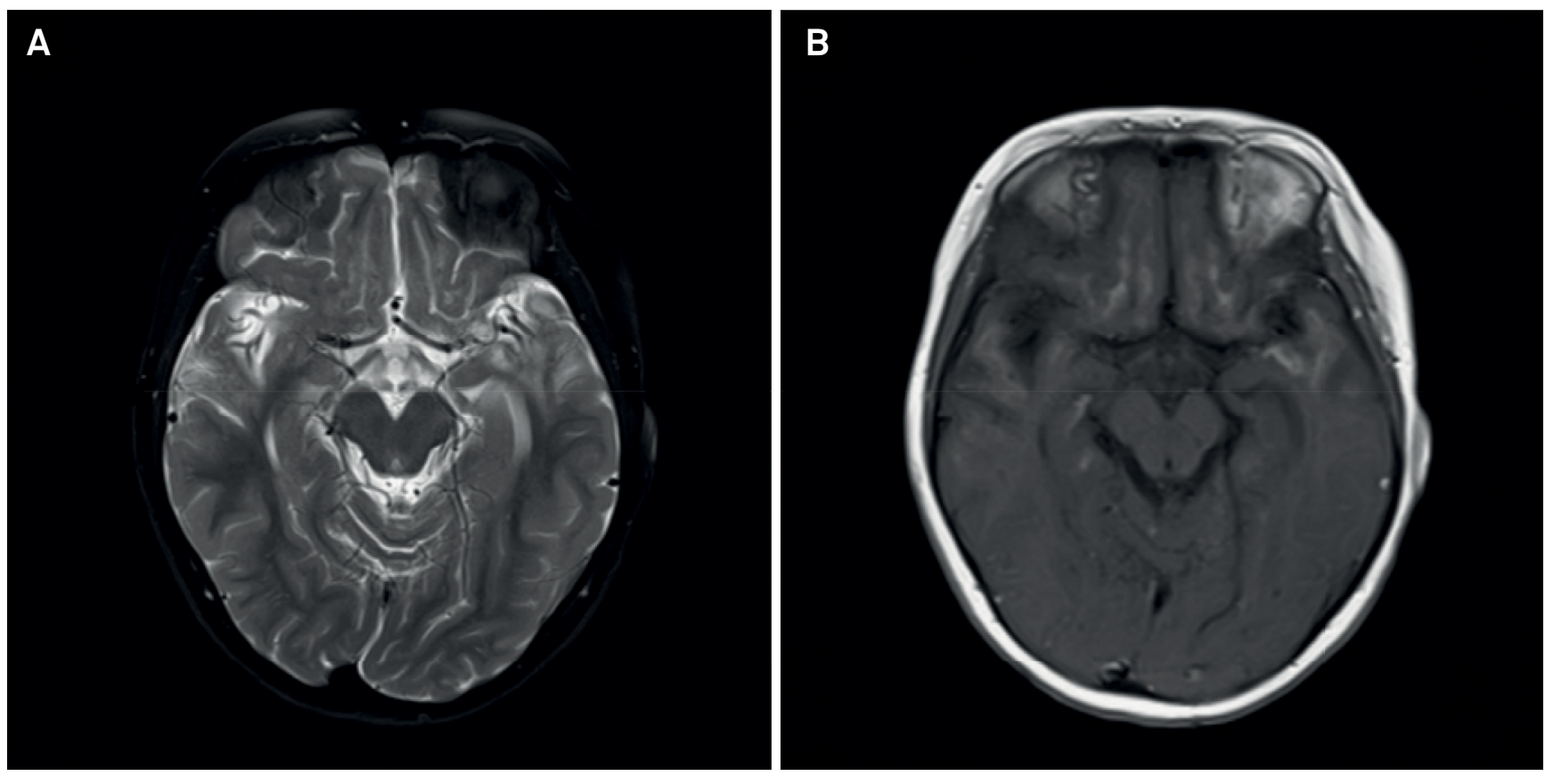

Figure 2. Follow-up brain MRI. Imaging four months after initial recognition of disseminated necrotizing leukoencephalopathy and cessation of inciting therapies demonstrates interval improvement in edema (A) and reduced extent of contrast enhancement (B).

\section{References}

1. Oka M, Terae S, Kobayashai R, Sawamura Y, Kudoh K, Tha KK et al. MRI in methotrexate-related leukoencephalopathy: disseminated necrotizing leukoencephalopathy in comparison with mild leukoencephalopathy. Neuroradiology. 2003;45(7):493-7.
2.

Laxmi SN, Takahashi S, Matsumoto K, Higan S, Kurihara N, Imaizumi M et al. Treatment-related disseminated necrotizing leukoencephalopathy with characteristic contrast enhancement of the white matter. Radiat Med. 1996 Nov-Dec;14(6):303-7. 